\title{
Traducción y transculturación del romanticismo europeo en Esteban Echeverría
}

\author{
Translation and Transculturation of European Romanticism in Esteban Echeverría \\ Tradução e transculturação do romantismo europeu em Esteban Echeverría
}

\section{Friedhelm Schmidt-Welle}

inSTITUTO IBERO-AMERICANO, BERLín, ALEMANIA

Doctor en Literatura por la Universidad Libre de Berlín, Alemania. Ha publicado Mexiko als Metapher. Inszenierungen des Fremden in Literatur und Massenmedien (tranvía, 2011), Multiculturalismo, transculturación, heterogeneidad, poscolonialismo. Hacia una crítica de la interculturalidad (Herder, 2011), Culturas de la memoria. Teoría, historia y praxis simbólica (Siglo XXI, 2012), La historia intelectual como historia literaria (El Colegio de México / Cátedra Humboldt, 2014), Transformationen der Erinnerung und der Wirklichkeit in der Literatur (Stauffenburg, 2014; con Olivia Díaz, Florian Gräfe y Juliana Pérez) y Nationbuilding en el cine mexicano desde la Época de Oro hasta el presente (Iberoamericana, 2015; con Christian Wehr). Correo electrónico: schmidt-welle@iai.spk-berlin.de

Artículo de reflexión

Documento accesible en línea desde la siguiente dirección: http://revistas.javeriana.edu.co

La versión original del texto se presentó en el taller "La producción, traducción y apropiación transregional de saberes: actores, instituciones y discursos", organizado por el Instituto Ibero-Americano, y llevado a cabo en Berlín el 10 y 11 de octubre de 2014. 


\section{Resumen}

En este artículo se analizan los procesos de traducción cultural, apropiación y transculturación del Romanticismo Europeo -sobre todo del francés- en la ensayística de Esteban Echeverría. En sus textos, existe una relación íntima entre romanticismo, liberalismo y modernidad. El autor se apropia de ciertos elementos de $l o$ romántico, como el concepto de la modernidad y los principios de la Revolución francesa, pero rechaza otros como la revolución estética, la formulación radical del sujeto moderno, la cultura popular como base de la cultura nacional, o la emancipación de las mujeres. La apropiación ecléctica del romanticismo no solamente sirve para autorizar la voz del letrado y su función social, sino también para legitimar el proyecto liberal de la independencia espiritual y cultural.

Palabras clave: romanticismo; traducción cultural; liberalismo; transculturación; Esteban Echeverría

\section{Abstract}

In this paper, we analyze

the processes of cultural translation, appropriation, and transculturation of European Romanticism - particularly the French - in the essays of Esteban Echeverría. In his writings, there is an intimate relationship between romanticism, liberalism, and modernity. The author appropriates certain elements of romance, such as the concept of modernity and the principles of the French Revolution, but rejects others such as the aesthetic revolution, the radical formulation of the modern subject, popular culture as the basis of national culture, and the emancipation of women. The eclectic appropriation of romanticism not only serves to entitle the voice of the literate and its social function, but also to legitimize the liberal project of spiritual and cultural independence.

Keywords: Romanticism; Cultural Translation; Liberalism; Transculturation; Esteban Echeverría

\section{Resumo}

Neste artigo analisam-se os processos de tradução cultural, apropriação e transculturação do Romantismo Europeu - sobretudo do francêsna ensaística de Esteban Echeverría. Nos seus textos existe estreito relacionamento entre romantismo, liberalismo e modernidade. $\mathrm{O}$ autor apropria certos elementos de o romântico, como o conceito da modernidade e os princípios da Revolução francesa, mas rejeita outros como revolução estética, formulação radical do sujeito moderno, cultura popular como base da cultura nacional, ou emancipação das mulheres. A apropriação eclética do romantismo não apenas serve para autorizar a voz do letrado e sua função social, mas também para legitimar o projeto liberal da independência espiritual e cultural.

Palavras-chave: romantismo; tradução cultural; liberalismo; transculturação; Esteban

Echeverría

Cómo citar este artículo:

Schmidt-Welle, Friedhelm. "Traducción y transculturación del romanticismo europeo en Esteban Echeverría". Cuadernos de Literatura 21.41 (2017): 114-130. https://doi.org/10.11144/Javeriana.cl21-41.ttre 


\section{Introducción}

Hasta los años 80 del siglo pasado, la literatura hispanoamericana producida entre 1830 y 1890 se ha interpretado de manera general como "romántica" (Varela Jácome), siendo calificada como "romanticismo tardío" y distinguiendo diferentes etapas como "el romanticismo realista" y el "romanticismo naturalista", entre otras (Alegría 48-71; Carilla 195). Aparte de los problemas que causan esas interpretaciones, que mezclan las denominaciones de épocas literarias, desvalorizándolas incluso para la enseñanza de la historia literaria -lo que he criticado en otras ocasiones (Schmidt-Welle "El liberalismo"; "Romanticismo/s") - la noción de "romanticismo tardío" indica también un problema general de la historiografía literaria de Hispanoamérica; es decir: su dependencia de las categorías de la historia literaria europea. En ese contexto, la noción de "romanticismo tardío" no es otra cosa que la aplicación de las teorías sociológicas de la modernización de la década de 1950, según la cual los países subdesarrollados llegarán al estado de la modernidad de manera tardía. Eso significa, grosso modo, que sus literaturas serían una mera imitación de las literaturas estadounidense y europeas, y que seguirían al pie de la letra los modelos estéticos de estas últimas.

Es en ese contexto en que la obra de Esteban Echeverría, letrado liberal progresista argentino de la época de la Independencia, se califica como "romántica" (Pérez 377), y su poema "Elvira, o la novia del Plata", publicado en 1832, a veces incluso es considerado el primer poema romántico en Hispanoamérica o hasta en la lengua española (Barcia y Weinberg 11).

Lo que me propongo en el presente artículo es rastrear el proceso de traducción cultural del romanticismo (o, mejor dicho, los romanticismos) europeo(s) en los textos de Echeverría y, mediante ese análisis, el proceso consiguiente de transculturación de las ideas románticas en sus textos programáticos. No se trata, entonces, de una interpretación de sus obras poéticas, sino de aquellos textos que dejan ver sus posturas ideológicas en cuanto al romanticismo, pero también a la cultura nacional y cuestiones de la modernidad. El análisis se concentra en tres niveles de la construcción de lo romántico: la figura del escritor romántico; la adaptación del liberalismo político, y la apropiación ecléctica del romanticismo estético.

\section{La figura del escritor romántico}

El contacto de Echeverría con los romanticismos europeos data de su viaje a Europa. Emprende ese viaje, según su biógrafo y amigo - y en cierto sentido el "hacedor del autor" (Fontana) - Juan María Gutiérrez, en octubre de 1825 
(citado en Echeverría 106), ${ }^{1}$ y se queda en París hasta 1830, tomando algunos cursos universitarios y moviéndose en los círculos intelectuales de hispanoamericanos, españoles y, según Gutiérrez, los de otros idiomas. Aparte de un viaje a Londres por un mes y medio, al parecer no se mueve más allá de los límites de la "capital cultural del siglo XIX" (Mercado 5-34). Echeverría escribe muy poco sobre esa estancia en París, en parte, como bien indica Andrea Pagni, porque la misma escritura de textos literarios en Argentina es, en esos momentos, más un proyecto que una realidad, y no existe la tradición genérica de las relaciones de viaje (Pagni 82).

Juan María Gutiérrez, primer biógrafo de Echeverría, es, en gran parte, el responsable de haber incluido los textos del escritor y amigo en el romanticismo; juicio general que encontramos en gran parte de la crítica posterior de su obra. Pero lo que me parece incluso más importante es que Gutiérrez construye a Echeverría como figura romántica par excellence (véase su recuento de la biografía en las Obras completas de Echeverría): de extrema sensibilidad y delicadeza, sufriendo de los nervios, enfermo del corazón, no solamente en el sentido fisiológico sino también en el psicológico, y padeciendo una extrema nostalgia por su país natal, a pesar de que su estado de salud había mejorado mucho durante su estancia en París. Lo interesante de esa construcción de la figura romántica es la tendencia a identificar al escritor con los protagonistas románticos de textos literarios o con el yo lírico, en el caso de la poesía. Más allá de esta figura débil, sensible y delicada tan frecuente en los romanticismos europeos, ahora es el escritor mismo el que se convierte en esa figura y se identifica de esa manera con el modelo vivencial y literario europeo. Gutiérrez anota lo siguiente: "Esta vida no es propiamente de acción, si por acción se entiende la parte que toma un ciudadano en las funciones públicas de su país" (citado en Echeverría 104). Y añade que Echeverría no había sido un hombre que hubiera podido vivir del comercio, sino que en su poesía "se desprende sobre el fondo obscuro de un pasado nebuloso la figura de un joven que, hastiado de goces sensuales y de liviandades pueriles, busca en la cultura de la inteligencia... pábulo a la actividad de la mente y del corazón" (citado en Echeverría 106). Pero la programática autoconciencia romántica de los escritos sobre fondo y forma muchas veces no se refleja en la poesía de Echeverría; es decir, la producción lírica no alcanza el nivel de reflexión sobre la conciencia del sujeto que el mismo escritor propone en sus demás textos (Halperin Donghi 31-34).

$1 \quad$ Todas las citas de Echeverría se toman de la edición de las Obras completas de 1951. 
Al mismo tiempo, la predilección por la vida intelectual y artística se conecta, tanto en los escritos de Echeverría como en los de su biógrafo, con la cuestión de la cultura nacional. Gutiérrez pone en el centro de la construcción de la figura romántica del escritor la cuestión de la añoranza de la patria. Afirma:

Echeverría no podía vivir largo tiempo lejos de las orillas del Plata. Su alma estaba encordada como un arpa eólica que sólo resonaba herida por las auras patrias. Pocas veces puede darse una armonía más íntima entre el hombre y el suelo, entre el alma y la naturaleza, entre la luz, el ambiente, y la inteligencia y la imaginación, como la que existía entre don Esteban Echeverría y el país en donde había brotado a la vida como una planta indígena. Era generoso como la tierra virgen, vasto en sus miradas como la llanura; de alma tranquila y tempestuosa a un tiempo como el mar dulce que tantas veces cantó el rumor de las crecientes que habían arrullado su cuna. (Citado en Echeverría 115)

En otras palabras, existe, según Gutiérrez, una relación íntima entre hombre y naturaleza, pero también entre la figura del intelectual romántico y la patria (Pérez 378). Una vez establecida esa conexión entre escritor romántico e ideario político, el romanticismo aparecerá como parte integral del liberalismo; es decir, se trata de lo que comúnmente se ha definido como "romanticismo social" (Picard; Roggiano 630), siguiendo la famosa frase de Victor Hugo según la que "el romanticismo no es, si no lo entendemos más que por su lado militante, otra cosa que el liberalismo en literatura" (Hugo 1147 ${ }^{2}$ ). Los romanticismos europeos se reducen, por tanto, al romanticismo social, y se niega que haya un romanticismo políticamente conservador, sobre todo entre algunos representantes de la nobleza (Chateaubriand, Eichendorff, etc.), que sienten una nostalgia por los tiempos feudales en un momento en que están a punto de perder sus viejos privilegios.

En cierto romanticismo social, en cambio, se equiparan la modernidad estética y la político ideológica; es decir, se trata de un proyecto de modernización que se despliega en todos los sentidos y todos los niveles sociales y culturales. Es en ese contexto en el que Echeverría se establece a sí mismo como hombre, letrado y escritor moderno, legitimando la autoridad de su función como letrado en la sociedad argentina mediante la autoconstrucción del escritor romántico liberal. En ese contexto, la transculturación del romanticismo social francés o, más bien, la de sus posturas ideológicas, sirve como

Traducción: FSW. 
legitimación de su propia función social para la modernización de la sociedad argentina poscolonial y la sustentación de su base ideológica.

\section{La adaptación del liberalismo político}

En los "Antecedentes" (Echeverría 153-154) a los escritos sobre la fundación de la Asociación de Mayo, Echeverría subraya el heroísmo de los mártires de la Generación del 37. Asimismo, en la "Ojeada retrospectiva" habla de la "religión de la Patria" y de la creencia en "su grandioso porvenir" (Echeverría 155). Así, la patria se convierte en el centro del pensamiento político, y su realización - que para él todavía no se ha dado porque, a diferencia de la independencia política, la independencia espiritual queda como proyecto para el futuro - solamente podría llevarse a cabo "bajo una bandera de fraternidad, igualdad y libertad" (157); es decir, siguiendo los ideales de la Revolución francesa. Al mismo tiempo, Echeverría construye una unidad y homogeneidad absolutas del pueblo argentino que se resiste al régimen colonial español:

... ningún pueblo se halló en mejor aptitud que el argentino para organizarse y constituirse, al nacer a la vida política. Nuestra sociedad entonces era homogénea; ni había clases, ni jerarquías, ni vicios, ni preocupaciones profundamente arraigadas; reunía en sí lo que el pueblo ideal de Rousseau, es decir, "la conciencia de un pueblo antiguo, con la docilidad de uno nuevo". (203-204)

Es decir, el intelectual liberal destaca dos aspectos del pueblo argentino: excepcionalidad y homogeneidad. La excepcionalidad le sirve para realizar una delimitación de la joven nación poscolonial con respecto a otras sociedades nacidas de la conquista y el régimen colonial de España. El liberalismo y el romanticismo sirven, en ese contexto, como "un cuerpo de doctrina sobre el cual apoyar la ruptura total con la herencia cultural española y fundar ... una plataforma ideológico-estética basada en ideas dominantes en la Europa moderna" (Roggiano 629). La homogeneidad es la base para la fundación de una sociedad utópica: una patria sin clases ni jerarquías; sin conflictos.

Más adelante, el autor expresa su decepción porque, en vez de haberse realizado esa fundación de la patria ideal siguiendo el modelo del contrato social, el régimen de Rosas introdujo "[t]iranía, tumulto, robos, saqueo, asesinato" (Echeverría 204). Lamenta la falta de instituciones orgánicas y de una educación política (205); no encuentra una doctrina política conforme con las costumbres argentinas que sirva de fundamento al Estado, ni una filosofía nacional o una literatura original que exprese la vida social de la Argentina 
(207). Además, las masas se quedan en la absoluta ignorancia, "tienen todos los vicios de la civilización sin ningunas de las luces que los moderan" (208). Es decir, la supuesta homogeneidad se ha convertido en una homogeneidad de la ignorancia; de la falta de ilustración — sin que el autor pudiera especificar o explicar las razones históricas de ese desarrollo político social-. Lo que queda implícito en la condenación del "pueblo" es la postura antirosista de Echeverría; su odio al caudillismo (Pérez 383-384). Para contrarrestar el estatus quo, Echeverría propone, en el "Dogma socialista", la subordinación de cualquier postura ideológica bajo el patriotismo: "... pensamos que tratándose de la Patria, debe sacrificarse hasta el amor propio" (Echeverría 226). En ese contexto, el lema de su ideología política es "Mayo, Progreso, Democracia". ¿Cómo debemos entender esas tres nociones?

"Mayo" es sinónimo de la posibilidad de regresar a los ideales de la revolución de 1810, e implica la crítica al régimen de Rosas. En ese sentido, el "Dogma socialista" se legitima históricamente como el regreso a los ideales del Movimiento de Independencia (Echeverría 228), untados por las políticas nacionales posteriores. Por "Progreso", Echeverría entiende una modernización del país que se desarrolla siguiendo el modelo europeo. Anota lo siguiente: "La Europa es el centro de la civilización de los siglos y del progreso humanitario. / La América debe, por consiguiente, estudiar el movimiento progresivo de la inteligencia europea; pero sin sujetarse ciegamente a sus influencias" (234). Obviamente, en esa afirmación se nota el dilema de un intelectual que tiene que legitimar el apego a la cultura modernizadora europea caracterizada por él mismo como cumbre del progreso civilizatorio, por una parte, y el afán de independizarse de ese mismo modelo político con el proceso de decolonialización. Por eso, afirma al mismo tiempo que

[c] ada pueblo tiene su vida y su inteligencia propia... La nacionalidad es sagrada. Un pueblo que esclaviza su inteligencia a la inteligencia de otro pueblo, es estúpido y sacrílego... Cuando la inteligencia americana se haya puesto al nivel de la inteligencia europea, brillará el sol de su completa emancipación. (235)

Como en parte del pensamiento decimonónico europeo, Echeverría mezcla una noción política, social y económica del progreso con una dimensión espiritual en la que la mentalidad del pueblo juega un rol importante; pero, en el proceso de traducción de la noción de progreso al contexto local argentino, deja de lado aquellas posturas románticas que precisamente critican el progreso, el proceso de industrialización y la creciente capitalización de la naturaleza en los países económicamente más avanzados en Europa. 
En "Continuación de las tradiciones", Echeverría aclara cómo entiende la noción de democracia. Según él, la Revolución de Mayo es la verdadera revolución de independencia, pero "[e]l principio de la omnipotencia de las masas debió producir todos los desastres que ha producido, y acabar por la sanción y establecimiento del despotismo" (Echeverría 248). Echeverría cree que el pueblo solo podrá ser soberano a partir de su educación, su ilustración, y es la Generación del 37 la que debe llevar a cabo esa tarea educativa (Echeverría 248-249; Halperin Donghi 90-92; Pérez 391). A la independencia política se tiene que añadir la de las ideas y costumbres (Echeverría 249-251) porque "somos independientes, pero no libres" (252); es decir, se necesita de la emancipación del espíritu americano (252-254). Los portavoces de esa visión son, en cada caso, los representantes de la Generación del 37; el programa elitista es formulado por el mismo Echeverría de una manera bastante abstracta. "Desde el símbolo se pasa al programa y desde ese programa se plantea que sólo los que lo anuncian son capaces de llevar al país más allá de los límites impuestos por la fracasada política unitaria" (Sosnowski 296).

¿Cómo se realizan los procesos de traducción cultural y transculturación con respecto al liberalismo y al romanticismo social europeos? En un principio, Echeverría retoma las ideas de la Revolución francesa, enfatizando algunos elementos del pensamiento socialista temprano como la idea de la igualdad de clases en su formulación saintsimoniana (Echeverría 236) - “... a cada hombre según su capacidad, a cada hombre según sus obras" (237) - o la idea cultivada por la foven Europa y su máximo representante, Giuseppe Mazzini, sobre la nación unida e igual, y la unión de Dios y la nación. De ahí su énfasis en el estado sagrado de la patria.

Pero la patria construida por el escritor argentino no es la que construyen los autores románticos europeos. Mientras que ellos se basan en la cultura popular y los mitos antiguos de fundación de la nación en el pasado (aunque esos mitos serían, en última instancia, ficcionales), para Echeverría, la nación misma es un proyecto a realizarse en el futuro, inacabado y además traicionado por el rosismo. Por eso el lema de "somos independientes pero no libres", que impregna gran parte de los debates literarios y culturales en Hispanoamérica hasta los años 60 del siglo XX. El dilema del escritor argentino, y ese otro dilema, están presentes en muchos letrados de las jóvenes naciones independientes; es la "falta" o negación de tradiciones políticas y culturales en las cuales se podría basar el patriotismo de la sociedad poscolonial (Schmidt-Welle, "El liberalismo sentimental hispanoamericano" 324326). Las dos líneas de pensamiento o tradición cultural que se ofrecen - la del poder colonial, por una parte, y la de lo autóctono, lo indígena, por otra - son inaceptables para los pensadores del liberalismo "romántico" como Echeverría. Por 
eso, no pueden basar la identidad nacional en tradiciones existentes o mitos de un pasado que serviría como fundamento de la patria en el sentido de la comunidad imaginada (Anderson). Más bien perciben la independencia como punto cero de la nación que debe construirse en el futuro, no a partir de la historia, sino de la naturaleza americana que, al mismo tiempo, no se convierte, como en el pensamiento romántico europeo, en espejo del estado de ánimo del sujeto, sino en paisaje; en última instancia exterior a ese sujeto, porque la naturaleza americana es, a la vez, símbolo de la identidad nacional y de la barbarie que impide la modernización de la sociedad poscolonial. El ejemplo más significativo al respecto en la obra de Echeverría es El matadero, y la crítica a la barbarie va en contra de la crítica a la civilización moderna e industrial de la filosofía europea de la época.

Si consideramos la noción de progreso en Echeverría, queda explícita la contradicción con la noción rousseauniana de pueblo "natural" y su crítica a la civilización europea. Mientras que Rousseau y los románticos europeos critican la modernización y la creciente industrialización, es decir, la modernización socioeconómica, el letrado argentino se declara en favor de esa misma modernización, siguiendo el esquema civilización y barbarie (Roggiano 629) que se sobrepone a la relación positiva del romanticismo con la naturaleza como espejo del alma y que es crítica de los vicios de la civilización europea.

El eclecticismo y la contradicción interna de esta apropiación del pensamiento romántico ${ }^{3}$ se encuentran en el centro de los debates sobre la modernidad que se llevan a cabo entre muchos letrados del siglo XIX en Hispanoamérica. El impulso antimoderno de los románticos no se traduce al pensamiento de los liberales hispanoamericanos porque, en las sociedades poscoloniales, el proceso de modernización industrial no ha comenzado en ese momento y es, más bien, un proceso anhelado por ellos.

La adaptación de las ideas democráticas del liberalismo social francés en Echeverría tampoco traduce los ideales de la Revolución francesa sin restricciones al contexto local argentino. Aunque el escritor afirme en el "Dogma socialista" que la libre asociación debe ser la base de la civilización y de la organización de la sociedad entre iguales (Echeverría 230-233), su idea de democracia supone el régimen de una élite de intelectuales liberales y la educación del pueblo; es decir, de las masas bárbaras. Echeverría se declara a favor, aunque sea de manera implícita, de la República de las Letras, y dentro de ella, los letrados juegan el rol de modernizadores y educadores de los demás. 


\section{La apropiación ecléctica del romanticismo estético}

En "Fondo y forma" se reúnen los escritos de Echeverría sobre cuestiones estéticas. Hay que considerar que esos artículos no se publicaron en vida del autor, sino que se basan en gran parte en sus conferencias en el Salón Literario que funcionaba en la trastienda de la librería de Marcos Sastre. En cuanto a la prosa, pero sobre todo con respecto a la poesía, Echeverría se identifica en un primer momento con el lema de Victor Hugo según el cual "el Romanticismo no es más que el Liberalismo en literatura" (Echeverría 472). "La poesía nacional", afirma el autor argentino, "es la expresión animada, el vivo reflejo de los hechos heroicos, de las costumbres, del espíritu, de lo que constituye la vida moral, misteriosa, interior y exterior de un pueblo" (483). Obviamente Echeverría se basa en el pensamiento filosófico de Herder según el cual el clima, la religión y las costumbres son los factores más importantes para la creación de una poesía con rasgos nacionales (460). Pero, a diferencia de Herder, no incluye el idioma en esa lista de aspectos o condiciones de la existencia de una literatura nacional. En parte, ese procedimiento indica otro dilema de los letrados hispanoamericanos después de la Independencia. No pueden convertir al idioma o al lenguaje en aspecto central de la mentalidad de un pueblo, porque lo comparten, no solamente con otras naciones hispanoamericanas, sino también con el antiguo régimen colonial; es decir, no sirve como criterio de distinción cultural o ideológica.

Como en sus escritos político-ideológicos, en los estéticos se construye una relación íntima entre romanticismo, modernidad y nación o patria. Según Echeverría, "cada pueblo o civilización [tiene] su poesía" (Echeverría 460), y el genio del poeta romántico (473) es la forma individual y máxima expresión de esa "poesía colectiva". En otras palabras, el poeta o incluso el letrado se convierte en el protagonista y portador ideal de la identidad nacional. La diferencia fundamental entre las distintas poesías, tanto individuales como colectivas, es decir, nacionales, radica en la forma y no en el contenido. ${ }^{4} \mathrm{El}$ romanticismo aparece como la individualización radical de la forma y, con ella, la negación del modelo o ideal estético del clasicismo (464). No es extraño, entonces, que Echeverría vea en la naciente literatura nacional un rechazo de toda idea de imitatio, la que considera estéril (472-473). Afirma que "[n]uestra

4 En cierto sentido, esa formulación radical de la preponderancia de la forma anticipa el pensamiento del formalismo ruso de a comienzos del siglo $\mathrm{XX}$ - aunque tendríamos que considerar que bajo "forma", Echeverría entiende la "expresión poética" de acuerdo con el pensamiento de la época-. 
cultura empieza: hemos sentido sólo de rechazo el influjo del clasicismo" (472). En cambio, admite la influencia de Victor Hugo como modelo teórico (471), y declara que las fuentes de toda poesía deben ser la verdad y la naturaleza (473).

En un breve apartado titulado "La situación y el porvenir de la literatura hispano-americana (1)" emprende una polémica con el intelectual español Alcalá Galiano. Afirma que la América es más emancipada que España, y por eso, esta última no puede funcionar como modelo literario para la naciente literatura hispanoamericana (Echeverría 509-514). Las literaturas contemporáneas deben aprovechar, más bien, los modelos franceses (513) de la escritura romántica entendida como la forma radical de la modernidad. Aquí, la visión sumamente positiva del romanticismo entra en una contradicción interna: por una parte, Echeverría niega cualquier modelo o imitación de formas extranjeras ajenas al genio del pueblo argentino o del individuo-escritor romántico. Por otra, considera - igual que en el caso de la idea del liberalismo político - que la civilización europea (o francesa, para ser más preciso) debe funcionar como modelo tanto ideológico como estético. De ahí también su polémica en contra de un clasicismo que en la literatura argentina, a diferencia de la francesa, es prácticamente inexistente. La lucha contra las viejas formas literarias en la joven república es, entonces, una lucha ficcional, sin sentido. No se lucha contra la esterilización de una literatura academicista, sino contra un modelo de vida cultural y literario que ni existe en el propio país. La razón para emprender esa lucha es, por una parte, la identificación con el liberalismo político y, por otra, la necesidad de seguir el modelo del romanticismo social francés y sobre todo las ideas de Victor Hugo como argumentos de autoridad del propio discurso.

Aunque en sus conferencias en el salón literario de Marcos Sastre, Echeverría no desarrolla más que un bosquejo provisional con respecto a la posibilidad de apropiación de las literaturas europeas de su momento, queda claro que retoma una serie de elementos del romanticismo para traducirlos al contexto local. A pesar de su contacto con el romanticismo inglés (Lord Byron) y el alemán (mediante su recepción en Madame de Staël), ${ }^{5}$ en Echeverría, el romanticismo se identifica con el romanticismo social francés como elemento ideológico estético o cultural del liberalismo. Si uno analiza su poesía (lo que no ha sido mi intento en ese artículo), verá que lo romántico en el escritor argentino no es la revolución

5 Según Gutiérrez, Echeverría lee a Shakespeare, Goethe, Schiller y especialmente a Byron (citado en Echeverría 110), pero las reglas de versificación las aprende con la literatura española (110111). Entre los escritores hispanoamericanos del siglo XIX, es común acuerdo ver en Goethe y Schiller autores del romanticismo, aunque en la historiografía literaria alemana se consideran representantes del Sturm und Drang y, más tarde, del clasicismo y no del romanticismo. 
estética que introduce la noción del sujeto moderno, como es el caso de los autores románticos europeos más radicales (Schmidt-Welle, "El liberalismo sentimental hispanoamericano"). Más bien, en él lo moderno y la modernidad son sinónimos de la modernidad social, económica y política; es decir, de la modernización. De esa manera, la contradicción existente entre modernización y modernidad estética; los impulsos antimodernos de muchos escritores románticos y, sobre todo, su idealización del buen salvaje (en Rousseau y Chateaubriand, por ejemplo), se pierden en el proceso de traducción y transculturación americana del romanticismo en los textos de Echeverría. En última instancia, no se puede ser antimoderno si no se ha llegado plenamente a la modernidad. Lo que queda, aparte de unos cuidadosos comienzos de la conquista del espacio público en los salones literarios como modelo de sociabilidad democratizadora, es la traducción cultural y la apropiación ecléctica y, a mi modo der ver, consciente, de los elementos románticos que pueden servir para la fundación de la nación y sobre todo de la cultura nacional. Al mismo tiempo, Echeverría se construye a sí mismo como letrado haciendo uso de la autoridad de la figura del máximo representante del romanticismo social francés. De esa manera, se adjudica una función social bien definida a sí mismo: la de representar al liberalismo y al romanticismo como formas (o expresiones) de lo moderno y del progreso.

\section{Traducción cultural y transculturación del romanticismo en Esteban Echeverría}

En Echeverría, el romanticismo europeo (o, mejor dicho, los romanticismos) se traduce(n) en un proceso de descontextualización y recontextualización parcial. Esa traducción cultural se lleva a cabo en tres niveles: la construcción de la figura del escritor romántico; la adaptación del liberalismo político, y la apropiación ecléctica del romanticismo estético. La descontextualización y recontextualización no significan que el contexto se entienda como noción estática en cuanto al espacio cultural. Más bien, se trata de una traducción cultural que se basa en diálogos transatlánticos y transculturales con complejos procesos de apropiaciones parciales, y su consiguiente inscripción y funcionalización en los nuevos contextos locales. Por supuesto, tenemos que considerar que esos diálogos, al menos en la época de Echeverría, son sumamente asimétricos en cuanto a las relaciones culturales entre metrópoli y periferia.

En el caso de Echeverría, la construcción del escritor romántico que se sirve de la voz y la autoridad del máximo representante del romanticismo social francés, Victor Hugo, funciona como legitimación de la función social del letrado en el proceso de la tan anhelada independencia espiritual y cultural. Se imagina una República de las Letras en la cual los escritores cumplen la tarea de educar al 
pueblo bárbaro para que este, en un futuro lejano, pueda ejercer su poder soberano. En ese contexto, el poeta se constituye a sí mismo como portador ideal de la identidad nacional y legitima, de esa manera, su rol político y su función social.

En Echeverría, es bien visible la relación íntima entre romanticismo, liberalismo y modernidad. En parte, la recepción del romanticismo social funciona como proceso de legitimación ideológica de la adaptación del liberalismo político. Por eso, el autor se apropia de ciertos elementos de lo romántico, como el concepto de la modernidad y los principios de la Revolución francesa; pero rechaza otros como la revolución estética, la formulación radical del sujeto moderno, la cultura popular como base de la cultura nacional, o la emancipación de las mujeres. La apropiación ecléctica del romanticismo no solamente sirve para autorizar la voz del letrado y su función social, sino también para legitimar el proyecto liberal de la independencia espiritual y cultural. En el caso de la fascinación romántica por la naturaleza, Echeverría la considera a medias definiéndola como una de las fuentes de la identidad y la mentalidad nacionales, por una parte, y rechazándola como símbolo de la barbarie, por otra.

Espero haber mostrado que en el escritor argentino se realizan diversos procesos de transculturación programáticos del romanticismo europeo en varios niveles. Los debates sobre las posibilidades actuales de emplear el concepto de transculturación muestran, a mi modo de ver, que la noción teórica puede considerarse válida para analizar procesos culturales en Hispanoamérica -al menos los procesos que han tenido lugar en el siglo XIX-. (Y yo diría que esa afirmación también es válida para gran parte del siglo XX). Pero la noción de transculturación tendría que liberarse de su esencialismo - ni termina en el mestizaje cultural que se imaginaba Fernando Ortiz ni en la unidad y homogeneidad de una literatura de la transculturación a nivel continental que propuso Ángel Rama-. Más bien, se trata de procesos inacabados y contradictorios en sí, debido a la situación poscolonial de Hispanoamérica, como se puede ver en el caso de la traducción cultural y la apropiación del romanticismo que se lleva a cabo en los textos y las posturas ideológicas de Esteban Echeverría.

\section{Obras citadas}

Alegría, Fernando. Historia de la novela hispanoamericana. $4^{\mathrm{a}}$ ed. México: Andrea, 1974. Impreso.

Anderson, Benedict. Imagined Communities. Reflections on the Origin and Spread of Nationalism. London: Verso, 1983. Impreso.

Barcia, Pedro Luis y Félix Weinberg. Homenaje a Esteban Echeverría 1805 - 1851. Buenos Aires: Academia Argentina de Letras Academia Nacional de la Historia, 2004. Impreso. 
Carilla, Emilio. El romanticismo en la América Hispánica. 2 tomos. Madrid: Gredos, 1975. Impreso.

Echeverría, Esteban. Obras completas. Buenos Aires: Antonio Zamora, 1951. Impreso.

Fontana, Patricio. "El crítico como hacedor de autores. Juan María Gutiérrez y las Obras completas de Esteban Echeverría". Historiografías literarias decimonónicas: la modernidad y sus cánones. Eds. Lidia Amor y Florencia Calvo. Buenos Aires: Eudeba, 2011. 175-187. Impreso.

Halperin Donghi, Tulio. El pensamiento de Echeverría.

Buenos Aires: Sudamericana, 1951. Impreso.

Hugo, Victor. "Préface" (al drama Hernani). Théatre complet.

Tome 1. París: Gallimard, 1963. 1147-1151. Impreso.

Mercado, Juan Carlos. Building a Nation. The Case of Echeverría.

Lanham - Londres: University Press of America, 1996. Impreso.

Pagni, Andrea. "El relato de viajes y la construcción de un lugar de enunciación para la literatura argentina: Alberdi, Echeverría y Sarmiento". The Colorado Review of Hispanic Studies 3 (2005): 73-98. Impreso.

Pérez, Alberto Julián. "Echeverría, la Revolución de Mayo y la literatura nacional". Alba de América. Revista Literaria 20.37-38 (2001): 377-403. Impreso.

Picard, Roger. Le Romantisme social. Nueva York: Brentano's, 1944. Impreso.

Roggiano, Alfredo. "Esteban Echeverría y el romanticismo europeo". Actas del Sexto Congreso Internacional de Hispanistas. Eds. Alan M. Gordon y Evelyn Rugg. Toronto: University of Toronto Department of Spanish and Portuguese, 1980. 629-631. Impreso.

Schmidt-Welle, Friedhelm. "El liberalismo sentimental hispanoamericano". Ficciones y silencios fundacionales. Literaturas y culturas poscoloniales en América Latina (siglo XIX). Ed. Friedhelm Schmidt-Welle. Madrid - Frankfurt: Iberoamericana - Vervuert, 2003. 317-336. Impreso.

Schmidt-Welle, Friedhelm. "Romanticismo/s y formación de la literatura nacional en México. Algunas hipótesis sobre la historia literaria del siglo XIX". Passages Pasajes - Passagen. Homenaje a Christian Wentzlaff-Eggebert. Eds. Virtudes AteroBurgos, Susanne Grunwald, Claudia Hammerschmidt, Valérie Heinen, Gunnar Nilsson y Pedro Piñero. Sevilla: Universidad de Sevilla, 2004. 599-610. Impreso.

Sosnowski, Saúl. "Esteban Echeverría: el intelectual ante la formación del Estado". Revista Iberoamericana 47.114-115 (1981): 293-300. Impreso.

Varela Jácome, Benito. "Evolución de la novela hispanoamericana en el XIX". Historia de la literatura hispanoamericana. Tomo 2: Del neoclasicismo al modernismo. Ed. Luis Iñigo Madrigal. Madrid: Cátedra, 1987. 91-133. Impreso. 


\section{Comentario de Vittoria Borsò}

(UNIVERSIDAD HEINRICH HEINE, DÜSSELDORF)

Friedhelm Schmidt-Welle explora el potencial del concepto de transculturación para la historiografía literaria. Partiendo de la tesis de que los conceptos de transculturación son independientes pero no libres, se pregunta acerca de su apego a las categorías de la historia literaria europea. El primer poema romántico "Elvira, o la novia del plata" (1832), del argentino Esteban Echeverría, se sitúa en la emergencia del romanticismo en América Latina; periodo en el que se supone que la traducción cultural consigue un proceso de transculturación de las ideas románticas. Como figura de intelectual romántico que escribe en favor de la construcción de una "patria", Esteban Echeverría representa la vertiente principal del romanticismo latinoamericano, demostrando su orientación hacia aquel tipo de romanticismo europeo en el que el liberalismo de Victor Hugo juega un papel fundamental. En América Latina, el liberalismo quiere decir la búsqueda de emancipación intelectual para la construcción de una futura cultura democrática. La transformación llevada a cabo por medio del traslado del romanticismo al nuevo mundo se encuentra entonces en la dimensión de la temporalidad que, en América Latina, se orienta al futuro, mientras que en Europa se dirige más bien hacia la búsqueda de las raíces culturales de la nación (Herder; Mazzini). De esta transculturación, en la que Schmidt-Welle encuentra comprobado el proceso de descontextualización y recontextualización parcial (el poeta es portador ideal de la identidad nacional; el resultado es la legitimación de su rol político), procede también el dilema del escritor argentino - un dilema que se encuentra en otras regiones de América Latina, como por ejemplo México (Juárez; Altamirano) —: la búsqueda de la emancipación a raíz de la Independencia coincide con la modernización de la patria y requiere la denigración del pasado, considerado como arcaico. Los indígenas aparecen como símbolos de la barbarie que impide la modernización de la sociedad poscolonial. Por ende, la apropiación ecléctica del romanticismo estético sirve para la fundación de la nación. Esta tarea de la literatura hace que el impulso antimoderno - esto es, la crítica de la modernización que fundamenta los romanticismos europeos- no se traduzca al pensamiento de los liberales latinoamericanos. Los letrados latinoamericanos son modernizadores y educadores de los demás, pues la emancipación y la democracia suponen el régimen de los intelectuales liberales y la educación del pueblo; es decir: de las "masas bárbaras" ${ }^{6}$ Schmidt-Welle constata, por ende,

6 Coincido plenamente con estas tesis. Confróntese con "Entre Alejandro de Humboldt y Maximiliano de Habsburgo: el largo camino hasta el "triunfo de la república"” (2010). 
la contradicción entre la modernización, prevalente en el romanticismo latinoamericano, y la modernidad estética que fundamenta los impulsos antimodernos de muchos escritores románticos europeos - entre otros, Rousseau o Chateaubriand-y su idealización de la cultura indígena. Estos impulsos se pierden en el proceso de transculturación americana del romanticismo.

Contrariamente a la distinción que se hace en Europa entre la modernización en el campo sociopolítico y la modernidad estética, crítica de este proyecto, en los comienzos genealógicos de los discursos sobre la modernidad en América Latina se establece la unión del proyecto de la nación y de la modernización. En palabras de Schmidt-Welle: "lo moderno y la modernidad son sinónimos de la modernidad social, económica y política; es decir, de la modernización".

La genealogía en la que desemboca la exploración de Schmidt-Welle acerca de los procesos de transculturación en la historiografía literaria no se puede sobrevalorar. El romanticismo demuestra la sintomatología subyacente en los discursos de los intelectuales latinoamericanos que prosigue hasta hoy en día, como hemos visto en la discusión de la "modernidad": el proyecto racionalista y progresista de la modernización, y no la "modernidad" tout court, es el locus de enunciación de la epistemología de la modernidad y de su crítica en América Latina.

Explorando las fases de descontextualización y recontextualización llevadas a cabo por la transculturación, Schmidt-Welle demuestra un resultado cuya dinámica tiene que ser considerada en su compromiso con la política, hasta la biopolítica. La íntima coalición entre política y literatura que resulta de este diagnóstico requiere, a mi modo de ver, ulteriores reflexiones acerca de los agentes del proceso transcultural. A título de ejemplo, resumo en lo siguiente los resultados de mi análisis acerca del entramado político-cultural-estético en el contexto de la transposición del Contrat social de Jean-Jacques Rousseau al Nuevo Mundo:

El punto crucial del Contrato social es la relación entre el individuo y el cuerpo social. Ahí reside, según Louis Althusser, la aporía del contrato. La manera en la que Rousseau resuelve dicha aporía es un "escándalo", pues la solución requiere "la aliénation totale de chaque associê" (Althusser 17). La estructura patológica del contrato social se manifiesta en la autoalienación del sujeto, debida no solamente a la introducción del poder ejecutivo como dispositivo de la representación del individuo singular, sino también al poder legislativo al que se debe entregar cada "asociado". Ahora bien, Simón Bolívar reconoce que el punto más difícil de la transposición del contrato social al Nuevo Mundo se encuentra en la relación entre el individuo y el cuerpo social. A esto se refiere explícitamente en el "Discurso de Angostura" (1819): "La libertad, dice Rousseau, es un alimento suculento pero 
de difícil digestión. Nuestros débiles conciudadanos tendrán que enrobustecer su espíritu antes que logren digerir el saludable nutritivo de la libertad" (Bolívar 65). Debido a la pluralidad de las etnias, a las diversidades raciales y a las heridas de la esclavitud, entre otras, el cuerpo social aparece a Bolívar como inconciliablemente fragmentado y precario. Ya en la "Carta de Jamaica" (1815) había propuesto el "cuerpo neutro" de un cuarto poder: el "Poder Moral", que contaría con la función de vigilar la seguridad del "pacto social" contra los ataques de los "indígenas", los esclavos negros y las diferentes etnias que ponían en peligro la salud del cuerpo social. También un análisis lingüístico de las distintas traducciones del Contrato social demuestra cómo el poder político configura su entendimiento fundando los sucesivos modelos sociales traducidos a América. La paranoia de un "cuerpo social" precario que excluye etnias peligrosas para su propia seguridad y progreso, se inscribe también en el imaginario de los textos de los liberales románticos que contribuyen a la fundación de la nación - me refiero, por ejemplo, a las novelas que se escriben en México durante la república restaurada de Benito Juárez (como El Zarco de Altamirano) - . En las novelas del regionalismo, como Doña Bárbara de Rómulo Gallego, este imaginario engendrará espacios distópicos en los que las existencias son reducidas a nudas vidas.

Los procesos transculturales y el imaginario tanto social como literario requieren una lectura política que concientice acerca de la violencia de un poder soberano, real en las dictaduras del siglo XX y latente en la historia política de América Latina. ${ }^{7}$

\section{Obras citadas}

Althusser, Louis. "Sur le Contrat social". L'impensé de fean-facques Rousseau.

Eds. Louis Althusser et al. París: Seuil, 1970. 5-42. Impreso.

Bolívar, Simón. "Discurso de Angostura". Escritos políticos. A.

Simón Bolívar. Madrid: Alianza, 1990. 61-83. Impreso.

Borsò, Vittoria. "Entre Alejandro de Humboldt y Maximiliano de

Habsburgo: el largo camino hasta el "triunfo de la república". Alemania

y el México independiente. Percepciones mutuas, 1810-1910. Eds. Karl

Kohut et al. México: Herder et al., 2010. 223-244. Impreso.

7 Remito a la lectura biopolítica de Pedro Páramo de Juan Rulfo por Alberto Ribas Casasayas ("Pedro Páramo. México y la necropolítica", conferencia dictada en el XXI Congreso Anual de Mexicanistas Juan Bruce Novoa, en Irvine del 14 al 16 de mayo de 2015). 